\title{
Research on Light Response Curve Fitting Model of Four Chamaenerion Plants on the Serzilla Mountains
}

\author{
Lusheng Wan ${ }^{1,2}$, Zhen Xing ${ }^{1,2,3}{ }^{*}$, Xinyue Chang1,2, Jiang Liu ${ }^{4}$, Guorong Zhang1,2 \\ ${ }^{1}$ College of Resources and Environment, Tibet Agriculture \& Animal Husbandry University, Nyingchi, China \\ ${ }^{2}$ Tibetan Featured Flower Research and Development Center of National Flower Engineering Technology Research Center, \\ Nyingchi, China \\ ${ }^{3}$ National Station for Field Observation and Research of Alpine Forest Ecosystem, Nyingchi, China \\ ${ }^{4}$ Food Science College, Tibet Agriculture \& Animal Husbandry University, Nyingchi, China \\ Email: *xztibetan@163.com
}

How to cite this paper: Wan, L.S., Xing, Z., Chang, X.Y., Liu, J. and Zhang, G.R. (2018) Research on Light Response Curve Fitting Model of Four Chamaenerion Plants on the Serzilla Mountains. American Journal of Plant Sciences, 9, 1630-1645. https://doi.org/10.4236/ajps.2018.98118

Received: May 25, 2018

Accepted: July 9, 2018

Published: July 12, 2018

Copyright (C) 2018 by authors and Scientific Research Publishing Inc. This work is licensed under the Creative Commons Attribution International License (CC BY 4.0)

http://creativecommons.org/licenses/by/4.0/

\begin{abstract}
In order to study the applicability of different light response models to the photoresponse curves of four species of Chamaenerion, four species of Chamaenerion collected from Serzilla were used as test materials. Four common photosynthetic models were used to fit the photosynthetic response curve of the leaves. The results show that: 1) The effect of different photosynthetic response models on photosynthetic response curve of the genus chromasia was different. The fitted value of the correction model of right angled hyperbola was closest to the measured value, the R2 was 0.998 , and RE was 0.216. 2) In terms of fitting the photosynthetic parameters, the initial quantum efficiency, light compensation point and dark respiration rate were suitable for fitting with non-right angle hyperbolic model. In terms of fitting the photosynthetic parameters, the initial quantum efficiency, light compensation point and dark respiration rate were suitable for fitting with non-right angle hyperbolic model. 3) The photosynthetic characteristics of $C$. angustifolium subsp. circumvagum reflect the negative response to high altitude radiation. Under strong radiation, the photosynthetic rate, apparent quantum efficiency, and light saturation point are low. On the other hand, $C$. conspersum has a positive response to high altitude radiation. $C$. angustifolium and $C$. latifolium has a higher light compensation point and higher light saturation point, but it is also positive for high altitude radiation. The response is only a choice of light intensity at different elevations, which also explains the distribution of $C$. angustifolium and C. latifolium in the salmonella with a single elevation, habitat, and slope.
\end{abstract}




\section{Keywords}

Alpine Plant, Chamaenerion, Optical Response Curve, Right Angle Hyperbolic Correction Model

\section{Introduction}

The plant chamaenerion is a medicinal ornamental plant for ecological restoration [1] [2] [3], has very high application value and has gradually become the hot spot in research on modern botanical drug [4] [5] [6] [7]. Now the response curve fitting models of the photosynthetic light are diversified. The four frequent models include rectangular hyperssions model, nonrectangular hyperssions model, exponential function model and modified model of rectangular hyperbola. The rectangular hyperssions model, nonrectangular hyperssions model and exponential function model can be used to fit an asymptote without an extreme, which cannot resolve the plant saturation intensity and maximum net photosynthetic rate by using the model equations [8] and can not reflect the light suppression phenomena after the plant reaches the saturation intensity [9]. The nonrectangular hyperssions includes the curve's curvature $\theta$ and approximates to the measured value in case of data fitting [10]. The corrected rectangular hyperssions model includes the coefficient $\beta$ and $\gamma$, so it not only fits the light saturation point and light compensation point and computes the solution of the maximum net photosynthetic rate, but also roughly ensures that the fitted values and computed values approximate to the measured values highly.

Some bad weathers such as low temperature, drought, strong radiation and strong winds exist in the Tibetan Plateau, so the plants in this area feature distinct physiological and ecological adaptation [11] [12]. The strong radiation in the Tibetan Plateau will easily affect photosynthesis of the plants. When the altitude increases, the flavone content will increase in the plants, so the alpine plants have the radiation resistance stronger than that of the low-altitude plants [13]. For response to the illumination radiation intensity, the photosynthetic rate of some plants [14] [15] will become strong with growth of the radiation and these plants can actively utilize the light energy. The photosynthetic rate of some plants [16] [17] will become weak with growth of the radiation in order to avoid damage to the leaves under the strong light and enter the preventive status. Some persons [18] [19] think that this phenomena is caused by low temperature. In addition, the light saturation point and light compensation point of the alpine plants are lower than those of the low-altitude plants [16].

Therefore, identifying the photosynthesis light response curve of the alpine plants is significant for research on the photosynthetic characteristics of the alpine plants [20]. Four frequent light response modes are used to fit the light response data of four chamaenerion plants in this paper, the applicability of several light response modes is discussed, and some basis are provided for reasonable 
cultivation and scientific management of four chamaenerion plants.

\section{Materials and Methods}

\subsection{Overview of Experimental Site}

The experiment was conducted in the Tibetan Featured Flower Research and development Center of the National Flower Engineering Technology Research Center. The experiment site is located in the rare and endangered garden plant cultivation base of Tibet Agriculture \& Animal Husbandry University in Bayi Town, Bayi District, Nyingchi City. It is located in the lower reaches of the Niyang River, with an altitude of $2970 \mathrm{~m}$. It belongs to the warm and humid climate in Southeast Tibet with annual average temperature of $8.6^{\circ} \mathrm{C}$, the average temperature of the hottest month of $15.6^{\circ} \mathrm{C}$, the average temperature of the coldest month of $0.2^{\circ} \mathrm{C}$, the extreme maximum temperature of $30.2^{\circ} \mathrm{C}$, the extreme minimum temperature of $-15.3^{\circ} \mathrm{C}, \geq 10^{\circ} \mathrm{C}$ accumulated temperature of 2 $225.7^{\circ} \mathrm{C}$ and frost-free period of $177 \mathrm{~d}$. There is no month with monthly average temperature of $\leq 0^{\circ} \mathrm{C}$ throughout the year. The number of days with daily average temperature of $\geq 10^{\circ} \mathrm{C}$ is 159.2 . The average annual rainfall is $634.2 \mathrm{~mm}$. The distribution of precipitation is uneven throughout the year, mainly in June-September (71.6\%). The average relative humidity, humidity coefficient, maximum snow thickness, annual hail days, annual thunderstorm days, annual strong wind (wind speed $\geq 17.0 \mathrm{~m} / \mathrm{s}$ ) days, annual sunshine hours, sunshine percentage, average atmospheric pressure and temperature coefficient are $71 \%$, $1.01,11 \mathrm{~cm}, 2.8 \mathrm{~d}, 28.3 \mathrm{~d}, 7.6 \mathrm{~d}, 1988.6 \mathrm{~h}, 46 \%, 70.6 \mathrm{kPa}$ and 8.3, respectively. The late frost appears latest in early May, and the early frost appears earliest in late September [21]. The experimental site is open, and free from shading, and the lighting, ventilation and irrigation conditions are good.

\subsection{Test Materials}

The test materials include some perennial plants such as $C$. angustifolium, $C$. angustifolium subsp. Circumvagum, $C$. conspersum and C. latifolium in the Serzilla Mountains, Linzhi, Tibet Autonomous Region. After the test materials are cultivated and survive at the Tibet characteristic flowers and plants $R \& D$ center of the National Flowers and Plants Engineering Technology R\&D center, they will be tested in the flower season.

\subsection{Collection Method of Light Response Curve}

The photosynthesis test is measured inside the greenroom at the Tibet Characteristics Flowers and Plants R\&D Center of the National Flowers and Plants Engineering Technology Research Center. The test is performed at AM 9:00 11:30 in which the weather is clear. The Li-6400 portable photosynthesis instrument (LiCior Inc., Lincoln, USA) is sued. The fitting LED red and blue light source leaf room is used for automatic measurement of photosynthesis-light response curve in the open gas circuit. The photosynthesis photon flux densities are 2000, 
$1800,1600,1400,1200,1000,800,600,400,200,100,50,25$ and $0 \mu \mathrm{mol} \cdot \mathrm{m}^{-2} \cdot \mathrm{s}^{-1}$. The $\mathrm{CO}_{2}$ density of the gas source is set as $400 \mu \mathrm{mol} \cdot \mathrm{mol}^{-1}$ in case of measurement. The left room temperature $25^{\circ} \mathrm{C} \pm 0.5^{\circ} \mathrm{C}$, the air flow is $500 \mu \mathrm{mol} \cdot \mathrm{s}^{-1}$. The mature leaves with the normal form of the middle and up part and without plant diseases and insect pests are selected. 3 robust plantlets are selected for each plant. 1 leaf is measured for each plantlet. Measurement is performed three times.

\subsection{Light Response Curve Model}

\subsubsection{Light Response Model and Parameter Fitting}

Now the light response curve models are diversified. Four typical response models are selected for this test, including rectangular hyperssions model, modified model of rectangular hyperbola, nonrectangular hyperssions model and exponential function model.

The mathematical expression of the rectangular hyperssions model [22] is described as follows:

$$
P_{n}(I)=\frac{\alpha I P_{\max }}{\alpha I+P_{\max }}-R_{d}
$$

In this equation, $P_{n}(I)$ is the net photosynthesis rate, $I$ is the photosynthesis photon flux density, $\alpha$ is the initial gradient of the light response curve, $P_{\max }$ is the maximum net photosynthetic rate and $R_{d}$ is the dark respiration rate.

The modified model of rectangular hyperbola [23] [24] for the plant photosynthesis to the light response is expressed as follows:

$$
P_{n}(I)=\alpha \frac{1-\beta I}{1+\gamma I} I-R_{d}
$$

In this equation, $\alpha$ is the initial gradient of the light response curve, $\beta$ and $\gamma$ are the coefficient, $I$ is the photosynthesis photon flux density, $R_{d}$ is the dark respiration, and the saturation intensity $I_{\text {sat }}$ is:

$$
I_{\text {sat }}=\frac{\sqrt{(\beta+\gamma) / \beta-1}}{\gamma}
$$

The maximum net photosynthetic rate $P_{\max }$ is expressed as follows:

$$
P_{\max }=\alpha\left(\frac{\sqrt{\beta+\gamma}-\sqrt{\beta}}{\gamma}\right)^{2}-R_{d}
$$

The nonrectangular hyperssions model [25] is expressed as follows:

$$
P_{n}(I)=\frac{\alpha I+P_{\max }-\sqrt{\left(\alpha I+P_{\max }\right)^{2}-4 \theta \alpha I P_{\max }}}{2 \theta}-R_{d}
$$

In this equation, $P_{n}(I)$ is the net photosynthesis rate, $I$ is the photosynthesis photon flux density, $\theta$ is the curve curvature, $\alpha$ is the gradient of the plant photosynthesis to the light response curve in case of $I=0$, namely the initial gradient of the light response curve, which is also called as the initial quantum efficiency. 
$P_{\max }$ is the maximum net photosynthetic rate and $R_{d}$ is the dark respiration rate.

The exponential equation [26] of the plant photosynthesis to the light response given by Bassman and Zwier is expressed as follows:

$$
P_{n}(I)=P_{\max }\left(1-\mathrm{e}^{-\alpha I / P_{\max }}\right)-R_{d}
$$

In this equation, the definitions of $P_{n}(I), \alpha, P_{\max }, R_{d}$ and $I$ are same as the above definitions.

\subsubsection{Calculation of Characteristic Parameters of the Light Response Curve}

The initial quantum efficiency, maximum net photosynthetic rate and dark respiration rate of different chamaenerion plants in Serzilla Mountains can be obtained via photosynthesis model fitting. The linear regression is performed for the net photosynthesis rate data under the low photosynthesis photon flux density $\left(\leq 200 \mu \mathrm{mol} \cdot \mathrm{m}^{-2} \cdot \mathrm{s}^{-1}\right)$. The intersection point between the regressive line and $\mathrm{X}$ axis $\left(P_{n}=0\right)$ is the light compensation point. The intersection point with $y=$ $P_{\max }$ is the light saturation point. For modified model of rectangular hyperbola, light saturation point and maximum net photosynthetic rate can be calculated by using the Equation (3) and (4). For the exponential function model, the light saturation point is the corresponding photosynthesis photon flux density [27] [28] of $0.9 P_{\max }$ or $0.99 P_{\max }$.

\subsection{Data Processing}

The Excel is used for statistical analysis and plotting of the data.

To further test precision of the fitting data and actual measured photosynthesis parameter, RE (the relative error) [29] is defined:

$$
R E=\left|y_{t}-\hat{y}_{t}\right| / y_{t}
$$

In this equation, $y_{t}$ is the measured values and $y_{t}$ is the fitting value. Smaller $R E$ indicates that the fitting value approximates to the measured values.

\section{Results and Analysis}

\subsection{Fitting and Comparison of Light Response Curve}

Shown as the Figure 1, the rectangular hyperssions model, nonrectangular hyperssions model, exponential function model and modified model of rectangular hyperbola are used to fit the photosynthesis light response curves of four chamaenerion plants on the Serzilla Mountains. Four models can fit the photosynthesis data of four test materials well and the coefficient $\mathrm{R}^{2}$ is between 0.964 and 0.999 . The pure photosynthesis rate of $C$. angustifolium, $C$. angustifolium subsp. Circumvagum and $C$. latifolium will significantly reduce with growth of the photosynthesis photon flux density, namely light suppression phenomena. The rectangular hyperssions model can accurately reflect such phenomena. The photosynthesis fitting values of a model for different plants are similar to the 


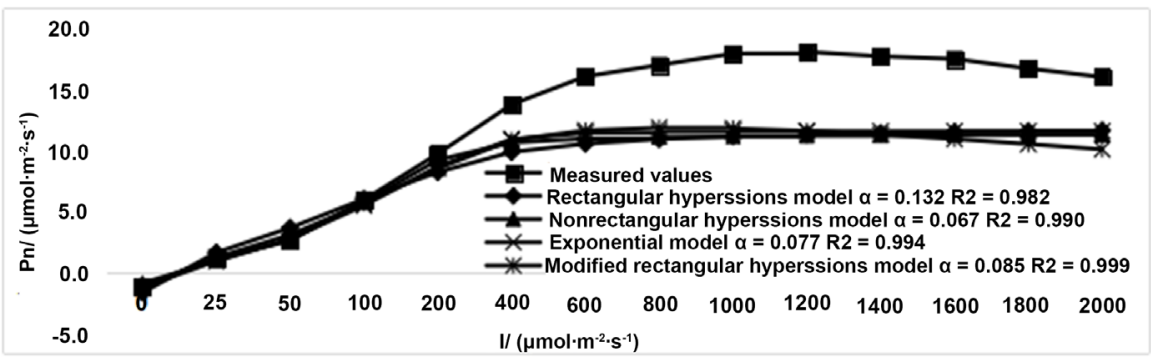

(a)

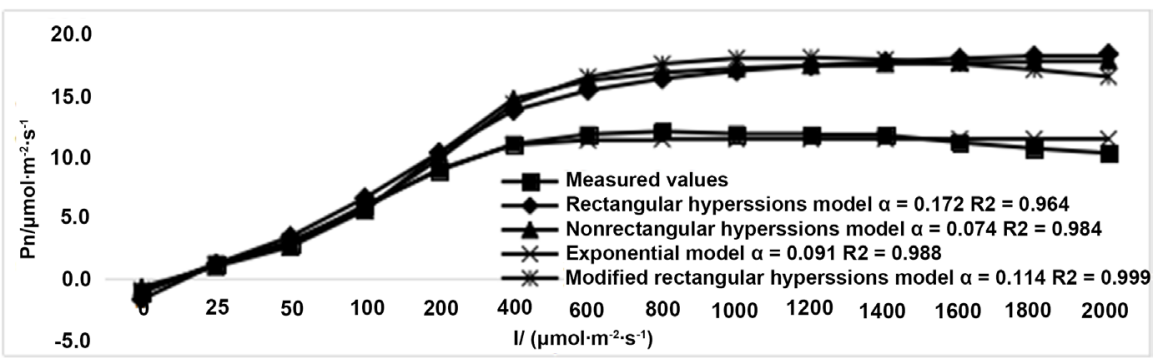

(b)

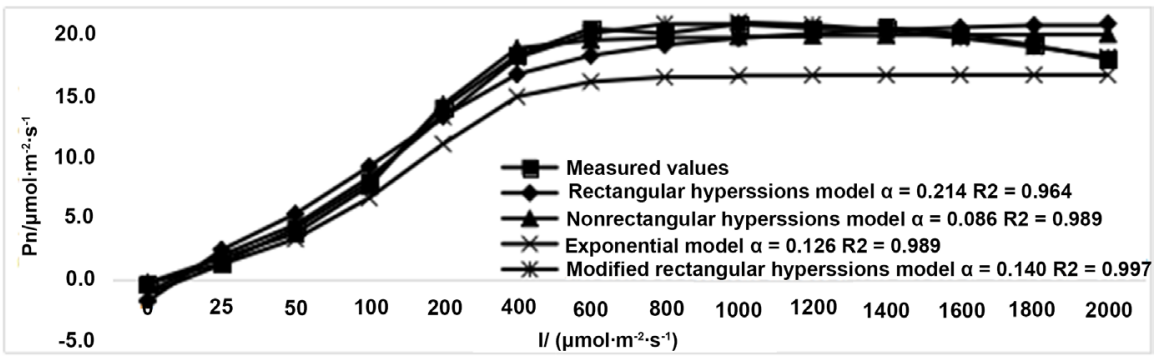

(c)

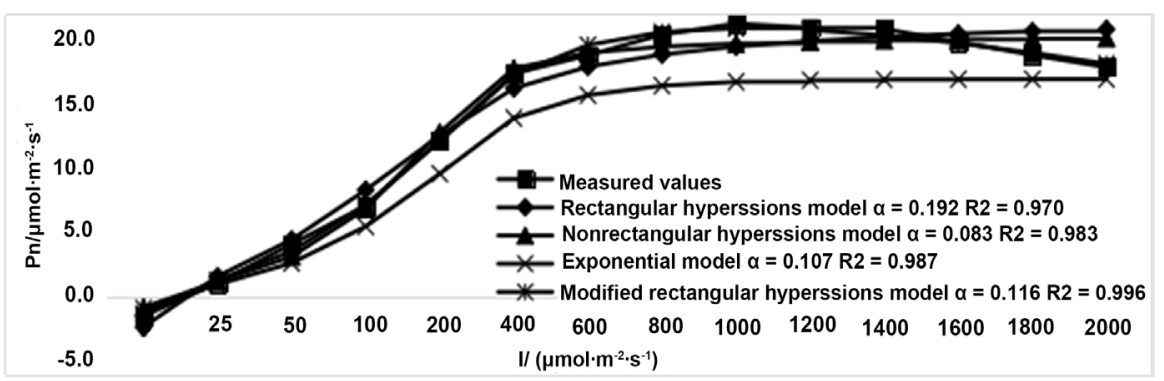

(d)

Figure 1. Photosynthetic-photoresponse curves of four species of Chamaenerion plants fitted by different models.

measured values under weak light conditions. When the photosynthesis photon flux density is more than $200 \mu \mathrm{mol} \cdot \mathrm{m}^{-2} \cdot \mathrm{s}^{-1}$, the exponential model fitting value is always smaller than the measured values and fitting values of other models. The diagram also shows that the fitting curves of the high determination coefficient are not much overlapped with the measured value curves.

It is known from Table $1, \mathrm{R}^{2}$ (0.998) of the modified model of rectangular hyperbola is the maximal determination coefficient, followed by $\mathrm{R}^{2}(0.989)$ of exponential function model and $\mathrm{R}^{2}(0.987)$ of nonrectangular hyperssions 
Table 1. Photosynthetic parameters and their data of four species of Chamaenerion plants fitted by four models.

\begin{tabular}{|c|c|c|c|c|c|c|c|c|c|}
\hline Model & Species/vari-eties & $\begin{array}{l}\text { Dark } \\
\text { respiration } \\
\text { rate }\end{array}$ & $\begin{array}{c}\text { Light } \\
\text { compensation } \\
\text { point }\end{array}$ & $\begin{array}{c}\text { Light } \\
\text { saturation } \\
\text { point }\end{array}$ & $\begin{array}{l}\text { Maximum net } \\
\text { photosynthetic } \\
\text { rate }\end{array}$ & $\mathrm{R}^{2}$ & $\begin{array}{l}\mathrm{R}^{2} \text { average } \\
\text { value }\end{array}$ & $\mathrm{RE}$ & $\begin{array}{l}\text { RE average } \\
\text { value }\end{array}$ \\
\hline \multirow{4}{*}{$\begin{array}{l}\text { Rectangular } \\
\text { hyperssions } \\
\text { model }\end{array}$} & $\begin{array}{l}\text { C. angustifolium } \\
\text { subsp. circumvagum }\end{array}$ & 1.602 & 10.560 & 292.380 & 13.788 & 0.964 & & 0.359 & \multirow{4}{*}{0.616} \\
\hline & C. angustifolium & 1.677 & 13.758 & 408.400 & 21.332 & 0.982 & \multirow[t]{2}{*}{0.970} & 0.393 & \\
\hline & C. conspersum & 1.947 & 9.852 & 333.600 & 25.298 & 0.964 & & 1.345 & \\
\hline & C. latifolium & 2.346 & 13.506 & 377.330 & 25.210 & 0.970 & & 0.366 & \\
\hline \multirow{4}{*}{$\begin{array}{c}\text { Nonrectangular } \\
\text { hyperssions } \\
\text { model }\end{array}$} & $\begin{array}{l}\text { C. angustifolium } \\
\text { subsp. circumvagum }\end{array}$ & 0.829 & 11.243 & 259.490 & 12.232 & 0.984 & & 0.242 & \multirow{4}{*}{0.306} \\
\hline & C. angustifolium & 0.675 & 10.086 & 359.710 & 18.750 & 0.990 & \multirow[t]{3}{*}{0.987} & 0.311 & \\
\hline & C. conspersum & 0.346 & 4.048 & 283.790 & 21.513 & 0.989 & & 0.275 & \\
\hline & C. latifolium & 0.799 & 9.660 & 326.080 & 21.739 & 0.983 & & 0.396 & \\
\hline \multirow{4}{*}{$\begin{array}{l}\text { Exponential } \\
\text { model }\end{array}$} & $\begin{array}{l}\text { C. angustifolium } \\
\text { subsp. circumvagum }\end{array}$ & 1.099 & 12.673 & 333.981 & 11.231 & 0.988 & \multirow{4}{*}{0.989} & 0.189 & \multirow{4}{*}{0.373} \\
\hline & C. angustifolium & 1.051 & 14.105 & 405.842 & 17.346 & 0.994 & & 0.241 & \\
\hline & C. conspersum & 1.057 & 8.600 & 326.787 & 21.062 & 0.989 & & 0.733 & \\
\hline & C. latifolium & 1.067 & 10.262 & 426.734 & 20.478 & 0.987 & & 0.329 & \\
\hline \multirow{4}{*}{$\begin{array}{l}\text { Modified model } \\
\text { of rectangular } \\
\text { hyperbola }\end{array}$} & $\begin{array}{c}\text { C. angustifolium } \\
\text { subsp. circumvagum }\end{array}$ & 1.183 & 11.090 & 844.411 & 11.872 & 0.999 & \multirow{4}{*}{0.998} & 0.063 & \multirow{4}{*}{0.216} \\
\hline & C. angustifolium & 0.916 & 11.095 & 1147.728 & 17.797 & 0.999 & & 0.064 & \\
\hline & C. conspersum & 1.151 & 8.519 & 965.082 & 22.073 & 0.997 & & 0.617 & \\
\hline & C. latifolium & 1.299 & 11.620 & 1023.592 & 21.388 & 0.996 & & 0.121 & \\
\hline \multirow{4}{*}{$\begin{array}{c}\text { The } \\
\text { measured } \\
\text { values }\end{array}$} & $\begin{array}{l}\text { C. angustifolium } \\
\text { subsp. circumvagum }\end{array}$ & 1.047 & 11.848 & 800.000 & 11.862 & & & & \\
\hline & C. angustifolium & 1.092 & 11.504 & 1200.000 & 18.062 & & & & \\
\hline & C. conspersum & 0.427 & 4.931 & 1000.000 & 21.888 & & & & \\
\hline & C. latifolium & 1.470 & 15.946 & 1000.000 & 23.067 & & & & \\
\hline
\end{tabular}

model. The minimal determination coefficient of the modified model of rectangular hyperbola is 0.970 . The determination coefficient indicates that four models can better fit photosynthesis light response curves of four chamaenerion plants. The fitting effect of four models are ranked from high to low as follows: modified model of rectangular hyperbola, exponential function model, nonrectangular hyperssions model and rectangular hyperssions model.

From the relative error average value, the minimal $\mathrm{RE}$ average value of the modified model of rectangular hyperbola is 0.216 , followed by RE (0.306) of nonrectangular hyperssions model and RE (0.373) of exponential function model. The rectangular hyperbola model has the maximal relative error average value and its RE average value is 0.616 . The relative error indicates that the similarity between the fitting values of four models and the measured values are ranked from high to low as follows: modified model of rectangular hyperbola, nonrec- 
tangular hyperssions model, exponential function model and rectangular hyperssions model.

To compare the determination coefficient and relative errors, the similarity between the fitting effect and fitting values of four models and the measured values complies with certain law and is not consistent, so $\mathrm{R}^{2}$ can only describe that the fitting degree of the model is higher, but it cannot guarantee that the fitting results are consistent with the measured value [30].

\subsection{Comparison of Light Response Characteristic Parameters of Different Chamaenerion Plants}

\subsubsection{Apparent Photosynthesis Quantum Efficiency and Initial Quantum Efficiency}

The apparent photosynthesis quantum efficiency is also called as the quantum efficiency under the light intensity, measures the utilization capability of the plants to the low-light quantum density and is also the basic parameter to reflect the plant light energy utilization and photosynthesis material productivity [31]. The line equation is used to fit the light response data under the weak light intensity $\left(\leq 200 \mu \mathrm{mol} \cdot \mathrm{m}^{-2} \cdot \mathrm{s}^{-1}\right)$ to get initial gradient, which is called as the apparent photosynthesis quantum efficiency [32]. Research on the light response characteristics of four chamaenerion plants on the Serzilla Mountains indicates that the apparent quantum efficiencies of four chamaenerion plants [33] are 0.0473 $\mu \mathrm{mol} \cdot \mathrm{m}^{-2} \cdot \mathrm{s}^{-1}$ (C. angustifolium subsp. Circumvagum), $0.0529 \mu \mathrm{mol} \cdot \mathrm{m}^{-2} \cdot \mathrm{s}^{-1}$ (C. angustifolium), $0.0760 \mu \mathrm{mol} \cdot \mathrm{m}^{-2} \cdot \mathrm{s}^{-1}\left(C\right.$. conspersum) and $0.0677 \mu \mathrm{mol} \cdot \mathrm{m}^{-2} \cdot \mathrm{s}^{-1}$ (C. latifolium).

It is known from Table 2, To compare the initial quantum efficiency for fitting of four models with the apparent quantum efficiency, the minimal average value of the relative error RE obtained from the fitting values of the nonrectangular hyperssions model is 0.299 , which is far less than that of other models. The initial quantum efficiency of the nonrectangular hyperssions to compare the initial quantum efficiency for fitting of four models with the apparent quantum efficiency, the minimal average value of the relative error RE obtained from the fitting values of the nonrectangular hyperssions model is 0.299 , which is far less than that of other models. The initial quantum efficiency from the nonrectangular hyperssions model approaches to the apparent quantum efficiency most. The initial quantum efficiency from the rectangular hyperssions model is far higher than the apparent quantum efficiency. The nonrectangular hyperssions model can better reflect the light energy utilization efficiency of four chamaenerion plants under the low light intensity on the Serzilla Mountains. The relative errors between the initial quantum efficiency and apparent quantum efficiency of models of different plants show that the fitting effect of four models for one plant is ranked from high to low as follows: $C$. latifolium, $C$. angustifolium and C. conspersum. The fitting values of $C$. angustifolium subsp. Circumvagum is very different from the measured values. 
Table 2. The relative error between the fitting value of initial quantum efficiency and the appwerent quantum efficiency of different models of light response parameters of four species of Chamaenerion.

\begin{tabular}{cccccc}
\hline Model & C. angustifolium subsp. circumvagum & C. angustifolium & C. conspersum & C. latifolium & Average value \\
\hline $\begin{array}{c}\text { Rectangular hyperssions model } \\
\text { Nonrectangular hyperssions } \\
\text { model }\end{array}$ & 2.630 & 1.501 & 2.162 & 1.520 & 1.953 \\
$\quad \begin{array}{c}\text { Exponential model } \\
\begin{array}{c}\text { Modified model of rectangular } \\
\text { hyperbola }\end{array}\end{array}$ & 0.569 & 0.272 & 0.264 & 0.092 & 0.299 \\
$\quad \begin{array}{l}\text { Average value } \\
\quad\end{array}$ & 0.928 & 0.454 & 0.863 & 0.405 & 0.662 \\
\hline
\end{tabular}

\subsubsection{Maximum Net Photosynthetic Rate}

The maximum net photosynthetic rate fitted by four models are compared with the measured values. The RE in the Table 3 shows that the average RE value of the modified model of rectangular hyperbola is 0.024 and its fitting value approximates to the measured value much. The fitting effect of the maximum net photosynthetic rate shows that the modified model of rectangular hyperbola can show the most accurate maximum net photosynthetic rate of four chamaenerion plants on the Serzilla Mountains in the four light response curve fitting models, followed by the nonrectangular hyperssions model. The difference between the fitting values of the rectangular hyperssions model and the measured values is maximum. For the fitting effect of four models to the maximum net photosynthetic rate of same plants, the minimal $\mathrm{RE}$ of the relative errors of $C$. conspersum is 0.055 . The RE value of $C$. angustifolium subsp. Circumvagum is 0.062 . The RE value of $C$. angustifolium is 0.068 . The RE value of the $C$. latifolium is 0.084. On the whole, the fitting effect of the fitting model of four light response curve is very accurate.

\subsubsection{Light Saturation Point}

From the RE values in the Table 4, when the fitting light saturation point of four models are compared with the measured values, the fitting value of the modified model of rectangular hyperbola approximates to the measured value much and its average RE value is 0.039 . From the fitting effect of the light saturation point, the modified model of rectangular hyperbola can show the most accurate light saturation points of four chamaenerion plants on the Serzilla Mountains, followed by the exponential function model. The difference between the fitting values of the nonrectangular hyperssions and the measured value reaches the maximum. The REV values of the exponential function model, rectangular hyperssions model and nonrectangular hyperssions mode are similar and are far bigger than the RE value of modified model of rectangular hyperbola. For the fitting effect of four models for the light saturation point of same plant, the RE value of the relative errors of the C. latifolium is 0.473 , which is similar to that of the $C$. angustifolium subsp. Circumvagum (RE is 0.487 ). The RE value of the $C$. angustifolium is 0.516 and is similar to that of C. conspersum ( $\mathrm{RE}$ value is $0.523)$. 
Table 3. The relative error between the maximum net photosynthetic rate fitting value and the measured value of light response parameters of four species of Chamaenerion.

\begin{tabular}{|c|c|c|c|c|c|}
\hline Model & C. angustifolium subsp. circumvagum & C. angustifolium & C. conspersum & C. latifolium & Average value \\
\hline Rectangular hyperssions model & 0.162 & 0.181 & 0.156 & 0.093 & 0.148 \\
\hline $\begin{array}{c}\text { Nonrectangular hyperssions } \\
\text { model }\end{array}$ & 0.031 & 0.038 & 0.017 & 0.058 & 0.036 \\
\hline Exponential model & 0.053 & 0.040 & 0.038 & 0.112 & 0.061 \\
\hline $\begin{array}{c}\text { Modified model of rectangular } \\
\text { hyperbola }\end{array}$ & 0.001 & 0.015 & 0.008 & 0.073 & 0.024 \\
\hline Average value & 0.062 & 0.068 & 0.055 & 0.084 & - \\
\hline
\end{tabular}

Table 4. The relative error between the fitting value of Light saturation Point and the measured value in different models of four species of Chamaenerion.

\begin{tabular}{cccccc}
\hline Model & C. angustifolium subsp. circumvagum & C. angustifolium & C. conspersum & C. latifolium & Average value \\
\hline $\begin{array}{c}\text { Rectangular hyperssions model } \\
\text { Nonrectangular hyperssions } \\
\text { model }\end{array}$ & 0.635 & 0.660 & 0.666 & 0.623 & 0.646 \\
$\quad \begin{array}{c}\text { Exponential model } \\
\begin{array}{c}\text { Modified model of rectangular } \\
\text { hyperbola }\end{array} \\
\text { Average value }\end{array}$ & 0.676 & 0.700 & 0.716 & 0.674 & 0.692 \\
$\quad$ & 0.583 & 0.662 & 0.673 & 0.573 & 0.623 \\
\hline
\end{tabular}

\subsubsection{Light Compensation Point}

When the fitting light compensation points of four model are compared with the measured value, from the RE values in the Table 5, the average RE value of the nonrectangular hyperssions model is 0.187 and its fitting value approximates to the measured values much. From the fitting effect of the light compensation point, the nonrectangular hyperssions model can better reflect the light compensation point of four chamaenerion plants on the Serzilla Mountains, followed by the modified model of rectangular hyperbola. The difference between the fitting value of the rectangular hyperssions and the measured is maximum. For fitting effect of different light response curve fitting models to the light compensation point of same plants, the minimal $\mathrm{RE}$ value of the relative errors of the $C$. angustifolium subsp. Circumvagum is 0.073 , the RE value of the $C$. angustifoliumRE is 0.145 . The $\mathrm{RE}$ value of the $C$. latifolium is 0.294 . The $\mathrm{RE}$ value of the C. conspersum is 0.662 .

\subsubsection{Dark Respiration Rate}

The RE in the Table 6 shows that the fitting dark respiration rate of the nonrectangular hyperssions mostly approximates to the measured value in the four models.

The average RE value is 0.309 . To compare the relative errors of the dark respiration rate of different plant models, the fitting effect of four models for same plant is ranked from high to low as follows: $C$. angustifolium subsp. Circumvagum, 
Table 5. The relative error between the fitting value of Light compensation Point and the measured value in different models of four species of Chamaenerion.

\begin{tabular}{|c|c|c|c|c|c|}
\hline Model & C. angustifolium subsp. circumvagum & C. angustifolium & C. conspersum & C. latifolium & Average value \\
\hline Rectangular hyperssions model & 0.109 & 0.196 & 0.998 & 0.153 & 0.364 \\
\hline $\begin{array}{c}\text { Nonrectangular hyperssions } \\
\text { model }\end{array}$ & 0.051 & 0.123 & 0.179 & 0.394 & 0.187 \\
\hline Exponential model & 0.070 & 0.226 & 0.744 & 0.356 & 0.349 \\
\hline $\begin{array}{c}\text { Modified model of rectangular } \\
\text { hyperbola }\end{array}$ & 0.064 & 0.036 & 0.728 & 0.271 & 0.275 \\
\hline Average value & 0.073 & 0.145 & 0.662 & 0.294 & - \\
\hline
\end{tabular}

Table 6. The relative error between the fitting value of dark respiration rate and the measured value in different models of four species of Chamaenerion.

\begin{tabular}{cccccc}
\hline Model & C. angustifolium subsp. circumvagum & C. angustifolium & C. conspersum & C. latifolium & Average value \\
\hline $\begin{array}{c}\text { Rectangular hyperssions model } \\
\text { Nonrectangular hyperssions } \\
\text { model }\end{array}$ & 0.530 & 0.536 & 3.560 & 0.596 & 1.306 \\
$\quad \begin{array}{c}\text { Exponential model } \\
\begin{array}{c}\text { Modified model of rectangular } \\
\text { hyperbola }\end{array}\end{array}$ & 0.209 & 0.382 & 0.189 & 0.457 & 0.309 \\
Average value & 0.049 & 0.037 & 1.476 & 0.274 & 0.459 \\
$\quad$ & 0.130 & 0.161 & 1.696 & 0.116 & 0.526 \\
\hline
\end{tabular}

C. angustifolium and C. latifolium. The difference between the fitting value of $C$. conspersum and the measured values is maximum. The nonrectangular hyperssions model can better show respiration role of the chamaenerion plant on the Serzilla Mountains under the dark environment.

\section{Conclusion}

Study on the selection of photo-response curve fitting model for four species of Chamaenerion in Serzilla Mountains, the results show that: 1) The effect of different photosynthetic response models on photosynthetic response curve of the genus chromasia was different. The fitted value of the correction model of right angled hyperbola was closest to the measured value, the R2 was 0.998 , and RE was 0.216 . 2) In terms of fitting the photosynthetic parameters, the maximum net photosynthetic rate and the light saturation point are suitable for fitting with the right-angle hyperbolic modified model. 3) The photosynthetic characteristics of $C$. angustifolium subsp. circumvagum reflect the negative response to high altitude radiation. Under strong radiation, the photosynthetic rate, apparent quantum efficiency, and light saturation point are low. On the other hand, $C$. conspersum has a positive response to high altitude radiation. C. angustifolium and $C$. latifolium has a higher light compensation point and higher light saturation point, but it is also positive for high altitude radiation. The response is only a choice of light intensity at different elevations, which also explains the distri- 
bution of $C$. angustifolium and $C$. latifolium in the salmonella with a single elevation, habitat, and slope.

\section{Discussion}

Four chamaenerion plants on the Serzilla Mountains are significant in medical applications such as antibiosis and antiphlogosis, antianxiety, tumor growth inhibition and anti-aging, regional ecological restoration such as burning, cutover land, roadside landslide and retaining wall edge, urban garden greening and ecological restoration construction. Their photosynthetic characteristics shall be further studied. It has important realistic significance for reasonable development and protection of chamaenerion plant resources in Tibet.

From fitting of photosynthesis parameters in this research, the maximum net photosynthetic rate and light saturation point are applicable to fitting of the modified model of rectangular hyperbola. The photosynthesis parameters fitted by the modified model of rectangular hyperbola are matched with the measured values, which is recognized and extensively applied by the researchers in most research on the light response fitting models and is well validated in this research. The modified model of rectangular hyperbola is recommended to study the photosynthesis light response data of the plants. The modified model of rectangular hyperbola is most suitable for fitting of the photosynthesis light response curves for four chamaenerion plants on the Serzilla Mountains, so the fitting values of modified model of rectangular hyperbola are used as the photosynthesis parameters (except apparent quantum efficiency) of four chamaenerion plants on the Serzilla Mountains. The fitting values are described as follows: the fitting value of the $C$. angustifolium apparent quantum efficiency is 0.0529 $\mu \mathrm{mol} \cdot \mathrm{m}^{-2} \cdot \mathrm{s}^{-1}$, the fitting value of the maximum net photosynthetic rate is 17.797 $\mu \mathrm{mol} \cdot \mathrm{m}^{-2} \cdot \mathrm{s}^{-1}$, the fitting value of the light saturation point is 1147.728 $\mu \mathrm{mol} \cdot \mathrm{m}^{-2} \cdot \mathrm{s}^{-1}$, the fitting value of the light compensation point is 11.095 $\mu \mathrm{mol} \cdot \mathrm{m}^{-2} \cdot \mathrm{s}^{-1}$, the fitting value of the dark respiration rate is $0.916 \mu \mathrm{mol} \cdot \mathrm{m}^{-2} \cdot \mathrm{s}^{-1}$, the fitting value of the $C$. angustifolium subsp. Circumvagum apparent quantum efficiency is $0.0473 \mu \mathrm{mol} \cdot \mathrm{m}^{-2} \cdot \mathrm{s}^{-1}$, the fitting value of the maximum net photosynthetic rate is $11.872 \mu \mathrm{mol} \cdot \mathrm{m}^{-2} \cdot \mathrm{s}^{-1}$, the fitting value of the light saturation point is $844.411 \mu \mathrm{mol} \cdot \mathrm{m}^{-2} \cdot \mathrm{s}^{-1}$, the fitting value of the light compensation point is $11.090 \mu \mathrm{mol} \cdot \mathrm{m}^{-2} \cdot \mathrm{s}^{-1}$, the fitting value of the dark respiration rate is 1.183 $\mu \mathrm{mol} \cdot \mathrm{m}^{-2} \cdot \mathrm{s}^{-1}$, the fitting value of the $C$. conspersum apparent quantum efficiency is $0.0760 \mu \mathrm{mol} \cdot \mathrm{m}^{-2} \cdot \mathrm{s}^{-1}$, the fitting value of the maximum net photosynthetic rate is $20.073 \mu \mathrm{mol} \cdot \mathrm{m}^{-2} \cdot \mathrm{s}^{-1}$, the fitting value of the light saturation point is 965.082 $\mu \mathrm{mol} \cdot \mathrm{m}^{-2} \cdot \mathrm{s}^{-1}$, the fitting value of the light compensation point is 8.519 $\mu \mathrm{mol} \cdot \mathrm{m}^{-2} \cdot \mathrm{s}^{-1}$, the fitting value of the dark respiration rate is $1.151 \mu \mathrm{mol} \cdot \mathrm{m}^{-2} \cdot \mathrm{s}^{-1}$, the fitting value of the C. latifolium apparent quantum efficiency is 0.0677 $\mu \mathrm{mol} \cdot \mathrm{m}^{-2} \cdot \mathrm{s}^{-1}$, the fitting value of the maximum net photosynthetic rate is 21.388

$\mu \mathrm{mol} \cdot \mathrm{m}^{-2} \cdot \mathrm{s}^{-1}$, the fitting value of the light saturation point is 1023.592 $\mu \mathrm{mol} \cdot \mathrm{m}^{-2} \cdot \mathrm{s}^{-1}$, the fitting value of the light compensation point is 11.620 
$\mu \mathrm{mol} \cdot \mathrm{m}^{-2} \cdot \mathrm{s}^{-1}$ and the fitting value of the dark respiration rate is 1.299 $\mu \mathrm{mol} \cdot \mathrm{m}^{-2} \cdot \mathrm{s}^{-1}$.

The light is the important environment factor to affect photosynthesis. The wide-range adaptation to the light shows that the plants have stronger adaptability to the environment. The plants with the lower light compensation point and higher light saturation point have stronger adaptability to the light environments. The plants with the higher light compensation point and lower light saturation point have weaker adaptability to the light environments [31]. The $C$. conspersum has lower light compensation point, higher light saturation point, higher net photosynthesis rate and wider illumination range in the research and is nearly distributed at different altitudes on the east and west slopes on the Serzilla Mountains. Such performance is similar to the Rheum tangutiCum [14], Kobresia humilis [15] and Polygonum viviparum L. [34] which have the active response to the strong radiation on the plateau. The $C$. angustifolium subsp. Circumvagum has higher light compensation point, lower light saturation point, narrow illumination adaptation range and photosynthesis feature of the shade-demanding plants. The photosynthetic characteristics of the $C$. angustifolium subsp. Circumvagum show passive response to the stronger radiation on the plateau and has lower photosynthesis rate, lower apparent quantum efficiency and lower light saturation point under the strong radiation. The $C$. angustifolium and $C$. latifolium has higher light compensation point and light saturation point, so they have weak adaptability to the light environment, but they have active response to the strong radiation on the plateau and can select the radiation with different light intensities at different altitudes. It can explain why the $C$. angustifolium and C. latifolium are distributed narrowly on the Serzilla Mountains. From the view of the light environment acclimation and adaptation, the plants on the plateau are difficult to grow in the areas with lower altitude and lower light intensities. The $C$. angustifolium, $C$. angustifolium subsp. Circumvagum and $C$. latifolium have significant suppression phenomena. The $C$. conspersum is most suitable for the applications under the high light intensities in Tibet. The daily change of photosynthesis and response to different $\mathrm{CO}_{2}$ concentrations shall be further studied for four plants. Research on response to different $\mathrm{CO}_{2}$ concentrations aims at the influences of the global weather change $\left(\mathrm{CO}_{2}\right.$ concentration and temperature increase) to the alpine plant photosynthesis and further derives their influences on other aspects in the Tibet plateau.

The alpine plant indicates the mountain plants growing on the high mountain tree line and higher and snow line. Now the research on the photosynthetic characteristics of the alpine plants mainly focuses on the North Pole and tundra zone and the research on the alpine plant at the middle and low latitude is missing [35]. The research on the photosynthesis of the chamaenerion plant on the Serzilla Mountains supplements research on the photosynthesis research of the alpine plants at the middle and low latitude. The research on the photosynthetic characteristics of the alpine plants in the Tibet plateau shows the following law: With growth of the altitude or effective photosynthesis radiation intensity, the 
photosynthetic characteristics parameters of the plant will grow or reduce. Some scholars [36] think that it may be caused by the survival regulation mechanism of the plant or be caused by consideration of single factor in research. The research on the photosynthetic characteristics of the alpine plants shall integrate interactive role or main component role of multiple environmental factors.

\section{Acknowledgements}

This study was financially supported by follow fund: Research on Tibet resources plant information system based on Android (2015XZ01G28); Comprehensive study on the diversity and landscape application techniques of Chamaenerion in Tibet (QC2015-43); Collection and utilization of medicinal flower resources in Tibet.

\section{References}

[1] Liu, Q.L. (2002) Garden Flowers and Plants Sidelights Europe (Serial II). Potted Flowers and Trees: Flowers and Plants Gardening, No. 6, 51.

[2] Xing, Z., Liu, Y. and Zhang, Q.X. (2011) Investigation on the Chamaenerion Ornamental Resoruces on Serzilla Mountains and Research on the C. conspersum Seedling Technology. China Wild Plant Resources, 30, 70-74.

[3] (2007) In: Flora of China, No. 13, 409-411. http://foc.eflora.cn/content.aspx?TaxonId=10630

[4] Yu, C.L. (1993) Traditional Chinese Medicine Cihai. Volume I. Chinese Medicine Science and Technology Press, Beijing.

[5] Bartfay, W.J., Bartfay, E. and Johnson, J.G. (2012) Gram-Negative and Gram-Positive Antibacterial Properties of the Whole Plant Extract of Willow Herb (Epilobium angustifolium). Biological Research for Nursing, 14, 85-89. https://doi.org/10.1177/1099800410393947

[6] Wang, L.X. (2008) Antianxiety Role of Aboveground Part Extract of C. angustifolium. Foreign Medicine. Plant Medicine Fascicule, 3, 6-7.

[7] Kosalec, I., Kopjar, N. and Kremer, D. (2013) Antimicrobial Activity of Willowherb (Epilobium angustifolium L.) Leaves and Flowers. Current Drug Targets, 14, 986-991. https://doi.org/10.2174/13894501113149990177

[8] Ye, Z.P. (2010) Research Progress for Photosynthesis Response Model to Light and $\mathrm{CO}_{2}$. Journal of Plant Ecology, 34, 727-740.

[9] Liang, W.B., Nie, D.L. and Wu, S.Z. (2014) Photosynthesis Light Response Curve and Model Fitting of Macropanax rosthornii. Economic Forest Researches, No. 04, 38-44.

[10] Ye, Z.P. and Li, J.S. (2010) Comparison Research of Photosynthesis Light Response for Modified Model of Rectangular Hyperbola and Nonrectangular Hyperssions Model. Journal of Jinggangshan University (Natural Science Version), 31, 38-44.

[11] Ma, L., Sun, X., Kong, X., et al. (2015) Physiological, Biochemical and Proteomics Analysis Reveals the Adaptation Strategies of the Alpine Plant Potentilla saundersiana at Altitude Gradient of the Northwestern Tibetan Plateau. Journal of Proteins, 112, 63-82.

[12] Shi, Z., Bai, D. and Lei, J. (2011) Research Progress of Physiological Ecology Adaptation of Alpine Plants to the Environment. Journal of Northwest Plant, 31, 1711-1718. 
[13] Albert, A., Sareedenchai, V., Heller, W., et al. (2009) Temperature Is the Key to Altitudinal Variation of Phenolics in Arnica montana L. cv. ARBO. Oecologia, 160, 1-8. https://doi.org/10.1007/s00442-009-1277-1

[14] Shi, S., Wang, X. and Li, H. (2006) Response of Medical Plant Anisodus tanguticus and Rheum tanguti Cum Photosynthesis of Tibet Plateau to the Strong Light. Molecule Plant (English Version), 32, 387-394.

[15] Han, F., Ben, G. and Shi, S. (1998) Comparison Research on the Antireversion Force of Kobresia humilis on Different Altitudes in Tibet Plateau. Ecology Journal, 18, 654-659.

[16] He, T., Wu, X. and Wang, X. (2005) Research on Photosynthetic Characteristics of Edelweiss at Different Altitudes. Journal of Northwest Plants, 25, 2519-2523.

[17] Shi, S., Cuiying, B., Zhao, X., et al. (2005) Effects of Supplementary uv b Radiation on Net Photosynthetic Rate in the Alpine Plant Gentiana Straminea. Acta Phytoecologica Sinica, 25, 231-235.

[18] Huang, W., Hu, H. and Zhang, S.B. (2016) Photosynthesis and Photosynthetic Electron Flow in the Alpine Evergreen Species Quercus guyavifoliain Winter. Frontiers in Plant Science, 7, 1511.

[19] Ma, F., Zhang, X.W., Chen, L.T., et al. (2013) The Alpine Homoploid Hybrid Pinus densata, Has Greater Cold Photosynthesis Tolerance than Its Progenitors. Environmental \& Experimental Botany, 85, 85-91.

https://doi.org/10.1016/j.envexpbot.2012.08.005

[20] Robert, E.S., Mark, A. and John, S.B. (1984) Kok Effect and the Quantum Yield of Photosynthesis. Plant Physiology, 75, 95-101. https://doi.org/10.1104/pp.75.1.95

[21] Meteorological Bureau of Tibet Autonomous Region (1979) Ground Climate Data of Tibet Autonomous Region. Meteorological Bureau of Tibet Autonomous Region.

[22] Baly, E.C. (1935) The Kinetics of Photosynthesis. Proceedings of the Royal Society of London Series B (Biological Sciences), 1, 218-239. https://doi.org/10.1098/rspb.1935.0026

[23] Ye, Z.P. (2007) A New Model for Relationship between Light Irradiance and the Rate of Photosynthesis in Oryza sativa. Photosynthetica, 45, 637-640. https://doi.org/10.1007/s11099-007-0110-5

[24] Ye, Z.P. and Yu, Q. (2008) A Coupled Model of Stomatal Conductance and Photosynthesis for Winter Wheat. Photosynthetica, 4, 637-640. https://doi.org/10.1007/s11099-008-0110-0

[25] Thornley, J.H.M. (1976) Mathematical Models in Plant Physiology. Academic Press, London, 86-110.

[26] Bassman, J. and Zwier, J.C. (1991) Gas Exchange Characteristics of Populus trichocarpa, Populus deltoids and Populus trichocarpa $\times$ P. deltoids Clone. Tree Physiology, 8, 145-159. https://doi.org/10.1093/treephys/8.2.145

[27] Wang, M., Feng, Y. and Li, X. (2006) Eupatorium Adenophorum and Fragrant Eupatorium Herb Form and Response of Photosynthetic Characteristics to the Phosphorus Nutrition. Journal of Application Ecology, 17, 602-606.

[28] Huang, H., Dou, X. and Sun, B. (2009) Comparison of Photosynthetic Characteristics of Two Jatropha curcas of Different Ecology Types in Summer. Journal of Ecology, 29, 2861-2867.

[29] Len, H., Qin, J. and Ye, K. (2014) Comparison of Photosynthesis Light Response Model of the Lotus Leaves under Different Light Illumination Environment. Journal of Application Ecology, 25, 2855-2860. 
[30] Liao, X., Liu, J. and Zhang, D. (2012) Photosynthesis Light Response Curve and Its Model Fitting of Wild Drepanostachyum luodianense. Journal of Central South University of Forestry Science and Technology, 32, 124-128.

[31] Jiang, B. (2004) Plant Physiological Ecology. Higher Education Press, Beijing, 65-66.

[32] Lin, B., Liu, J. and Xiao, S. (2006) Daily Dynamics Analysis of the Photosynthesis Physiological and Ecological Features of the Vetiver Grass in Western Guangdong. Application Ecology Journal, 17, 2041-2045.

[33] Wan, L., Xing, Z. and Chang, X. (2018) Research on the Light Response Characeristics of Four Chamaenerion Plants on Serzilla Mountains (English). Asian Agricultural Research, 6, 61-65.

[34] Wei, J., Ben, G. and Yu, H. (1998) Comparison of Photosynthetic Characteristics of Polygonum Viviparum Growing at Different Altitudes in the Qinghai Plateau. Journal of Biophysics, 14, 530-536.

[35] Wang, Y., Gao, H. and Liu, Y. (2013) Adaptation Mechanism of Alpine Plant Photosynthesis to the Threat. Journal of Application Ecology, 24, 2049-2055.

[36] Can, J. and Xue, L. (2018) Research Progress for Photosynthesis Physiological Property of Alpine Plant. Journal of Ecology, 37, 245-254. 